\title{
Association of Body Weight and Female Sexual Dysfunction: A Case Control Study
}

\author{
Mosayeb Mozafari ${ }^{1}$; Javaher Khajavikhan ${ }^{2}$; Molouk Jaafarpour ${ }^{3,{ }^{*}}$; Ali Khani ${ }^{1}$; Ashraf \\ Direkvand-Moghadam ${ }^{4}$; Fatemeh Najafi ${ }^{1}$ \\ ${ }^{1}$ Department of Nursing, Faculty of Nursing and Midwifery, Ilam University of Medical Sciences, Ilam, IR Iran \\ ${ }_{2}^{2}$ Imam Khomeini Hospital, Ilam University of Medical Sciences, Ilam, IR Iran \\ ${ }^{3}$ Department of Midwifery, Faculty of Nursing and Midwifery, Ilam University of Medical Sciences, Ilam, IR Iran \\ ${ }^{4}$ Psychosocial Injuries Research Center, Ilam University of Medical Sciences, Ilam, IR Iran \\ *Corresponding Author: Molouk Jaafarpour, Department of Midwifery, Faculty of Nursing and Midwifery, Ilam University of Medical Sciences, Ilam, IR Iran. Tel: +98-8412227116, Fax: \\ +98-8412227116, E-mail: jaafarpourm@gmail.com
}

Received: October 19, 2014; Revised: December 7, 2014; Accepted: December 13, 2014

\begin{abstract}
Background: Obesity is rapidly increasing worldwide with negative effects on women's health, psychosocial factors and quality of life. Female sexual dysfunction (FSD) is a major public health problem that is worrying for many women physically, emotionally and socially. Objectives: The purpose of this study was to investigate the association of body weight with FSD and sexual satisfaction, in Ilam, western Iran, in 2010 to 2011.

Patients and Methods: This was a case-control study on 120 women aged 18-50 years [64 with FSD (case), 64 without FSD (control)] married, from Ilam-IR, who were interviewed as per the Iranian version of Female Sexual Function Index (FSFI). Body mass index (BMI) and waist-to-hip ratio (WHR) were recorded by researchers. The subjects were randomly selected from primary health centers.

Results: FSFI score was significantly lower in overweight women $(\mathrm{P}<0.05)$. FSFI strongly correlated with body mass index $(\mathrm{BMI})(\mathrm{r}=-0.68$, $\mathrm{P}<0.001)$ and waist-to-hip ratio $(\mathrm{r}=-0.29, \mathrm{P}<0.05)$ in women with FSD. Of sexual function parameters, there was a strong and inverse correlation between BMI and arousal $(\mathrm{r}=-0.71, \mathrm{P}<0.001)$, lubrication $(\mathrm{r}=-0.61, \mathrm{P}<0.001)$, orgasm $(\mathrm{r}=-0.52, \mathrm{P}<0.001)$ and satisfaction $(\mathrm{r}=$ $-0.54, \mathrm{P}<0.001)$, while pain $(\mathrm{r}=-0.12, \mathrm{P}>0.05)$ and desire $(\mathrm{r}=-0.17, \mathrm{P}>0.05)$ did not correlate with BMI. There was an association between BMI and extreme satisfaction $(r=-0.28, P<0.05)$. Extreme physical pleasure $(r=-0.19, P>0.05)$ and extreme emotional satisfaction $(r=-0.16$, $\mathrm{P}>0.05)$ were not correlated with BMI.

Conclusions: Overweight and obesity negative affect sexuality in women with sexual dysfunction. A systematic evaluation of sexual function to disclose a cause and effect relationship between obesity and FSD is suggested.
\end{abstract}

Keywords:Body Mass Index; Obesity; Women; Sexuality

\section{Background}

Obesity is a significant public health problem, which is quickly increasing worldwide (1-3). In 2005, according to WHO estimate, approximately 1.6 billion adults were overweight and at least 400 million adults were obese worldwide (4).

A prevalence of $30 \%$ of adult population in the United States, $11 \%$ in the UK and $10 \%$ in Italy were reported (5). Obesity is associated with diseases including type II diabetes, hypertension, cardiovascular disease, osteoarthritis and a major cause of preventable mortality (1, 6-9). As estimated, 325000 mortality and $4.3 \%$ to $5.7 \%$ of health care costs (approximately 39-52 billion dollars) are allocated to obesity annually (10). Obesity has also a negative effect on sexual function $(11,12)$, body image (13) self-esteem (5, 14 ) and quality of life $(15,16)$.

Sexuality is a central part of individual's life (5), which its disruption, affects women's health, psychosocial factors significantly and causes emotional distress, lead- ing to relationship problems $(17,18)$. The prevalence of sexual dysfunction among all women is $25 \%$ to $63 \%$. If female sexuality is disturbed, consequences may be family disputes and divorce and reproduction is also affected (19). Research shows that obesity is associated to specific sexual dysfunctions such as loss of desire, poor sexual function and avoidance of sexual encounters. This would negatively affect patients' sexual life (9). Most research has focused on morbidly obese men $(20,21)$. There have been few studies on women $(22,23)$. A number of studies showed an association between BMI (body mass index) and FSD (Female Sexual Dysfunction). While, some others suggested no relationship between them (4).

\section{Objectives}

Understanding complex interactions between obesity and other risk factors of sexual dysfunction is poorly 
and insufficiently investigated. Therefore, the aim of this study was to investigate the association between body weight and sexual dysfunction in Kurd women from Ilam, western Iran.

\section{Patients and Methods}

This was a case-control study on 120 women [64 with FSD (case group), 64 without FSD (control group)], who were attending the primary health centers of Ilam University of Medical Sciences (Western Iran) from September 2010 to September 2011. The data extract center was governmental. The sample size was determined using the information obtained from a pilot study with 15 patients and the following formula:

$$
\begin{aligned}
& \mathrm{n}=\left(\mathrm{Z}_{1-\alpha / 2}+\mathrm{Z}_{1-\beta}\right)^{2}\left(\mathrm{f}_{1}^{2}+\mathrm{f}_{2}^{2}\right) /\left(\mathrm{m}_{1}+\mathrm{m}_{2}\right)^{2} \approx 64 \\
& \alpha=5 \% \\
& \mathrm{Z}_{1-\alpha / 2}=\mathrm{Z} 0.975=1.96 \\
& 1-\beta=80 \%=0.84 \text { (expected power) }
\end{aligned}
$$

f1 and $\mathrm{f}_{2}$ (An estimate of the standard deviation of BMI in the two groups with and without FSD respectively 4.5 and 3.1 were obtained in a pilot study).

$\mathrm{m} 1$ and $\mathrm{m} 2$ (An estimate of the mean of BMI in the two groups with and without FSD, respectively 26.4 and 24.5 were obtained in a pilot study).

The inclusion criteria included aged $18-50$ years, married, being Muslim and resident of Ilam. The exclusion criteria included women with chronic or severe medical illnesses or psychiatric illnesses, diabetes mellitus, gynecological surgery, lower urinary tract symptoms, pelvic trauma, polycystic ovarian syndrome, abnormal thyroid function, drug abuse, infertility and menopause state.

\subsection{Sampling}

A multiple stage random sampling design was used. In the first stage, using stratified random sampling, city of study was divided into four sections according to geographical location. Secondary, of each section one primary health center was selected using simple randomization (health centers NO: 3, 4, 7, 10). Women were randomly selected by simple random sampling from the record list of the health center at our institution. From each of the health centers, 16 case and 16 control subjects were selected.

Women accepted an interview and were available for a 1-hour face-to-face interview by midwifes. Using a standard questionnaire of demographic characteristics, subject's age, duration of marriage, type of residence, menarche age, frequency of sexual intercourse per week, educational level, smoking, age of the husband, number of children, contraception use and occupational status were assessed in all women.

Height and weight were recorded with centimeters and balance. We used the WHO classification of BMI (weight $(\mathrm{kg}) /\left(\right.$ height $\left.\mathrm{m}^{2}\right)$ and Women with FSD were divided according to BMI in normal weight (BMI $<25)$ or overweight/obese (BMI $\geq 25$ ). Waist-to-hip ratio (WHR) was calculated as waist circumference in centimeters divided by hip circumference in centimeters.

\subsection{Assessment of FSD}

FSD was evaluated with the Iranian version of the Female Sexual Function Index (FSFI) (24). The questionnaire assessed sexual functioning or problems during the last four weeks. According to the FSFI, sexual function domains consisted of sexual desire, arousal, lubrication, orgasm, satisfaction and pain during sexual intercourse. Sexual desire was assessed as frequency and desire level with two questions. Arousal was assessed as frequency, level, confidence and satisfaction with four questions. Lubrication was assessed as frequency, difficulty, frequency of maintaining and difficulty in maintaining with four questions. Orgasm was assessed as frequency, difficulty and satisfaction with three questions. Satisfaction was assessed as the amount of closeness with partner, sexual relationship and overall sex life with three questions. Pain was assessed as pain frequency during vaginal penetration and pain frequency following vaginal penetration with three questions.

The prevalence of sexual dysfunction was also calculated for each domain and compared between the groups. Therefore, sexual dysfunction for each domain was considered in the presence of a desire score of 3.3 or less (score range 1 to 5), an arousal score of 3.4 or less (score range 0 to 5), a lubrication score of 3.4 or less (score range 0 to 5), an orgasm score of 3.4 or less (score range 0 to 5 ), a satisfaction score of 3.8 or less (score range 0 or 1 to 5 ) and a pain score of 3.8 or less (score range 0 to 5 ). For each six domains, a score was calculated and the total score was obtained by adding six domain scores. The total score ranged from 2 to 36 . A total score of more than 28 was considered normal female sexual function and a total score of less than 28 was considered sexual dysfunction. Interviewer (midwife) matched respondents on various social attributes in an interview averaging 45 minutes. The interviewer was a same midwife in whole study.

Three questions assessed the degree of satisfaction regarding the main opposite-sex partner. Respondents were first asked to rate how physically pleasurable they found sex with their current regular partner (not at all pleasurable, slightly, moderately, very or extremely pleasurable), then asked how satisfied they were with sexual relationship overall and how emotionally satisfying they found the relationship (not at all satisfied to extremely satisfied) (4).

\subsection{Validity and Reliability}

The FSFI was previously described by Rosen et al. (25). The Iranian version of the FSFI was previously validated by Mohammadi Kh et al. (24). To determine the validity of the Iranian version of the FSFI, content validity was used. The questionnaire was given to 10 faculty members of Ilam University of Medical Sciences and was used after 


\section{Mozafari Met al.}

revision. To determine the reliability of questionnaire, Cronbach's alpha test was used. The reliability of the Iranian version of the FSFI was 0.83 .

\subsection{Ethical Consideration}

The study was approved by the Institutional Committee of Ethical Practice of our institution, and all women gave an informed written consent $(\mathrm{EC} / 88 / \mathrm{H} / 259$, date: 1 | Dec/2009).

\subsection{Statistical Analysis}

All statistical analyses were performed using SPSS, version 16 (SPSS Inc, Chicago, IL,USA). Categorical data were expressed as percentages. Values were presented as mean \pm SD. One-way ANOVA and independent t-test were used to compare parametric sexual function scores. Pearson correlation coefficient or Spearman rank order correlation test and regression analyses were performed when appropriate. $\mathrm{P}<0.05$ was considered significant.

\section{Results}

Eight subjects from case group were excluded due to exclusion criteria. None of the control group were excluded. Clinical and general characteristics of women are shown in Table 1. There was no significant difference in anthropometric measures (BMI and WHR) between the two groups of women with or without FSD.

The lists of FSFI score as well as sexual function scores for each sexual function parameter are shown in Table 1. There were significant differences in each parameters between the two groups of women. FSFI score was significantly lower in overweight/obese women (20.45 \pm 9.4) (Table 2).

FSFI strongly correlated with BMI $(r=-0.68, \mathrm{P}<0.001)$ in women with FSD. Of six sexual function parameters, pain $(r=-0.12, P>0.05)$ and desire $(r=-0.17, \mathrm{P}>0.05)$ did not correlate with BMI; while, there was a strong and inverse correlation between BMI and arousal $(\mathrm{r}=-0.71, \mathrm{P}<$ $0.001)$, lubrication $(r=-0.61, P<0.001)$, orgasm $(r=-0.52$, $\mathrm{P}<0.001)$ and satisfaction $(\mathrm{r}=-0.54, \mathrm{P}<0.001)$. Age had a significant correlation with FSFI. WHR correlated with FSFI score $(\mathrm{r}=-0.29, \mathrm{P}<0.05)$ (expect for desire and pain, $\mathrm{P}>0.05$ ) (Table 3).

There was a weak association between BMI and extreme satisfaction $(\mathrm{r}=-0.28, \mathrm{P}<0.05)$. Extreme physical pleasure $(r=-0.19, P>0.05)$ and extreme emotional satisfaction $(r=-0.16, P>0.05)$ were not correlated with BMI (Table 4). The Regression Analyses of FSFI score with BMI are show in (Table 5).

\begin{tabular}{|c|c|c|c|}
\hline Parameters & Women With FSD $(n=56)$ & Women Without FSD $(n=64)$ & P Value \\
\hline Age, y & $32.8 \pm 2.1$ & $32.1 \pm 3.1$ & 0.14 \\
\hline Menarche age, $y$ & $13.1 \pm 2.1$ & $13.6 \pm 2.8$ & 0.11 \\
\hline BMI, $\mathrm{kg} / \mathrm{m}^{2}$ & $27.3 \pm 4.6$ & $22.5 \pm 2.8$ & 0.001 \\
\hline WHR & $0.93 \pm 0.03$ & $0.81 \pm 0.02$ & 0.01 \\
\hline Smoking & & & 0.48 \\
\hline Yes & 2 & 3 & \\
\hline No & 54 & 64 & \\
\hline \multicolumn{4}{|l|}{ Education } \\
\hline Primary school & $5(8.9)$ & $6(9.3)$ & 0.18 \\
\hline High school & $46(82.1)$ & $49(76.5)$ & 0.26 \\
\hline Graduate & $5(8.9)$ & $9(14.00)$ & 0.08 \\
\hline FSFI score & $21.89 \pm 2.8$ & $29.46 \pm 3.1$ & 0.001 \\
\hline Desire & $3.1 \pm 0.7$ & $4.3 \pm 0.5$ & 0.001 \\
\hline Arousal & $3.1 \pm 0.9$ & $4.5 \pm 0.7$ & 0.001 \\
\hline Lubrication & $3.0 \pm 0.3$ & $5.1 \pm 0.5$ & 0.001 \\
\hline Orgasm & $2.9 \pm 0.5$ & $5.2 \pm 0.3$ & 0.001 \\
\hline Satisfaction & $3.5 \pm 0.6$ & $5.1 \pm 0.4$ & 0.001 \\
\hline Pain & $4.3 \pm 0.6$ & $4.9 \pm 0.3$ & 0.001 \\
\hline
\end{tabular}

${ }^{\mathrm{a}}$ Data are presented as Mean \pm SD and No. (\%). 
Mozafari Met al.

\begin{tabular}{|c|c|c|c|}
\hline Parameters & Normal Weight, BMI $<25(n=28)$ & Overweight/Obese, BMI $\geq 25(\mathrm{n}=28)$ & PValue \\
\hline Age, $y$ & $31.8 \pm 2.4$ & $32.1 \pm 2.1$ & 0.18 \\
\hline BMI, $\mathrm{kg} / \mathrm{m}^{2}$ & $23.3 \pm 1.1$ & $28.8 \pm 3.6$ & $<0.001$ \\
\hline WHR & $0.82 \pm 0.05$ & $0.94 \pm 0.07$ & $<0.05$ \\
\hline Mean menarche age & $13.4 \pm 1.1$ & $13.5 \pm 1.4$ & 0.16 \\
\hline FSFI score & $20.45 \pm 9.4$ & $16.2 \pm 2.8$ & $<0.05$ \\
\hline Desire & $3.43 \pm 0.7$ & $2.3 \pm 0.8$ & $<0.05$ \\
\hline Arousal & $3.1 \pm 0.9$ & $2.1 \pm 0.6$ & $<0.05$ \\
\hline Lubrication & $3.1 \pm 0.6$ & $2.18 \pm 0.9$ & $<0.05$ \\
\hline Orgasm & $2.83 \pm 0.9$ & $1.91 \pm 0.5$ & $<0.05$ \\
\hline Satisfaction & $3.04 \pm 0.8$ & $2.1 \pm 0.8$ & $<0.05$ \\
\hline Pain & $4.7 \pm 0.5$ & $4.6 \pm 0.7$ & $>0.05$ \\
\hline
\end{tabular}

a Data are presented as Mean \pm SD.

Table 3. Correlation of FSFI Score With BMI and Clinical Parameters in Obese Women With FSD ${ }^{\mathrm{a}}$

\begin{tabular}{|c|c|c|c|c|c|c|c|}
\hline $\begin{array}{l}\text { Charac- } \\
\text { teristic }\end{array}$ & FSFI score & Desire & Arousal & Lubrication & Orgasm & Satisfaction & Pain \\
\hline Age & $\mathrm{r}=-0.71, \mathrm{P}<0.001$ & $r=-0.62, P<0.001$ & $\mathrm{r}=-0.43, \mathrm{P}<0.05$ & $\mathrm{r}=-0.48, \mathrm{P}<0.05$ & $r=-0.56, P<0.001$ & $\mathrm{r}=-0.61, \mathrm{P}<0.001$ & $r=-0.44, P<0.05$ \\
\hline BMI & $r=-0.68, P<0.001$ & $r=-0.17, P>0.05$ & $r=-0.71, P<0.001$ & $r=-0.61, P<0.001$ & $\mathrm{r}=-0.52, \mathrm{P}<0.001$ & $\mathrm{r}=-0.54, \mathrm{P}<0.001$ & $\mathrm{r}=-0.12, \mathrm{P}>0.05$ \\
\hline WHR & $r=-0.29, P<0.05$ & $r=-0.15, P>0.05$ & $r=-0.26, P<0.05$ & $\mathrm{r}=-0.32, \mathrm{P}<0.05$ & $r=-0.38, P<0.05$ & $r=-0.39, P<0.05$ & $r=-0.17, P>0.05$ \\
\hline
\end{tabular}

a Abbreviations: BMI, body max index; WHR, waist-to-hip ratio; FSD, female sexual dysfunction; FSFI, Female Sexual Function Index.

Table 4. Correlation of BMI With Sexual Satisfaction in Obese Women With FSD

\begin{tabular}{lc}
\hline Characteristic & BMI \\
\hline extreme physical pleasure & $r=-0.19, P>0.05$ \\
extreme sexual satisfaction & $r=-0.28, P<0.05$ \\
extreme emotional satisfaction & $r=-0.16, P>0.05$ \\
\hline
\end{tabular}

Table 5. Regression Analyses of FSFI Score With BMI ${ }^{\text {a, b }}$

\begin{tabular}{|c|c|c|c|c|c|c|c|}
\hline FSFI score & FSFI score & Desire & Arousal & Lubrication & Orgasm & Satisfaction & Pain \\
\hline \multicolumn{8}{|l|}{ BMI } \\
\hline B & -1.50 & -0.26 & -0.01 & -0.16 & -0.47 & -0.05 & -0.42 \\
\hline Std. Error & 0.06 & 0.04 & 0.05 & 0.05 & 0.04 & 0.05 & 0.04 \\
\hline$\beta$ & -0.91 & -0.96 & -0.05 & -0.36 & -1.00 & -0.15 & -1.77 \\
\hline $\mathbf{t}$ & -23.80 & -6.62 & -0.32 & -3.02 & -11.58 & -1.04 & -3.47 \\
\hline Pvalue & $0.00^{\mathrm{a}}$ & 0.07 & $0.02^{b}$ & $0.003^{b}$ & $0.00^{\mathrm{a}}$ & $0.04^{b}$ & 0.14 \\
\hline
\end{tabular}

a $\mathrm{P}<0.001$.

b $\mathrm{P}<0.05$.

\section{Discussion}

FSD is a major public health problem (26) and is worrying for many women physically, emotionally and socially (19). Obese women compared with men experience more sexual problems (9). A number of researchers (27, 28) have shown that improving quality of life is positively related to weight loss, while other studies (7) failed to cor- roborate such associations. In this study, we found an association between body weight and sexual dysfunction, which is consistent with a number of pervious studies (5, 18, 29). We also did not find an association between BMI and physical pleasure or emotional satisfaction, while there was a significant association between BMI and 
sexual satisfaction. This is consistent with the findings of Smith et al. (4) and Adolfsson et al. (30), who found that overweight people did not differ in sexual satisfaction from people of normal weight and contrasted with Melin et al. who found that obese women reported significantly lesser satisfaction with their sexual life (3). In addition, Bajos et al. showed no differences in the percentage of respondents who were very satisfied with their sexual lives in different BMI categories (23).

Studies on women have reported conflicting results (5). Several studies reported a positive correlation between higher BMI and sexual problems $(5,18,29)$ infertility (2) and partner dissatisfaction $(17,31)$. While some others showed no association between obesity and sexual dysfunction $(1,32,33)$ or satisfaction (30).

Previous researches examined the impact of bariatric surgery on sexual function using a QoL instrument and revealed positive effects (9). Kirchengast et al. found that body weight and BMI in women significantly reduced sexual interest (34). Brody found that hip size was negatively associated with a lower frequency of penile-vaginal intercourse (35). Esposito et al. showed that women with metabolic syndrome have an increased prevalence of sexual dysfunctions compared with matched control women (26). Assimakopoulos et al. showed that bariatric surgery is associated with significant BMI reduction, depressive symptom alleviation and improvement in all domains of sexual function except for orgasm (9). In the US survey, obese men and women reported fewer sexual partners than non-obese individuals (23). Bajos et al. (23) and Smith et al. (4) found no difference in sexual dysfunction between obese or overweight women compared to women with a normal BMI. It is unknown whether overweight women have sexual dysfunction more than nonobese ones. In young women, clinical data shows an unclear association between obesity and sexual satisfaction. However, it seems that weight loss helps to improve sexual performance in overweight women. Improved sexual function after weight reduction in obese young women is probably due to change in sex hormones, estrogen and androgens and improvement of body image (36).

In previous studies, it was suggested that there are three possible mechanisms through which obese people may have sexual impairment: a) insulin resistance and associated hormonal changes, b) dyslipidemia and related drugs, and c) psychological problems (5). Psychological factors (such as poor sexual self-esteem leading to difficulty in allowing or initiating sex) or biological factors (such as musculoskeletal problems) might also be involved (23).

The strength of our study was the use of the Iranian version of the FSFI, which was used to investigate FSD, a version not used in previous Iranian FSD researches. We did a case-control study across a wide range of body weight and in contrast to mailed surveys, comorbidities were assessed and verified by interviewers. A limitation of our study was that discussing sexual issues is a sensitive matter and can be subject to report bias.
Another limitation of our study was assessing only married women and excluding unmarried, separated or divorced ones (because of cultural barriers). Women who were separated or divorced may be more at risk of FSD, which may have falsely raised the prevalence of FSD if included in the study.

In conclusion, we showed that in women with FSD, obesity affects sexuality function. Overweight women were more likely to lack interest in sexual relationship than women with normal BMI. This finding emphasizes the need for systematic evaluation of sexual function in this patient population to disclose a cause and effect relation between obesity and FSD.

\section{Acknowledgements}

We thank Ilam University of Medical Sciences, participants, coordinators and data reviewers who assisted in this study.

\section{Authors' Contributions}

Mosayeb Mozafari, Javaher Khajavikhan, Molouk jaafarpour, Ali Khani, Ashraf Direkvand-Moghadam and Fatemeh Najafi participated in the study design, data analysis, literature review, preparation and editing the manuscript.

\section{Funding/Support}

This study was supported by Ilam University of Medical Sciences (NO. 88021).

\section{References}

1. Kadioglu P, Yetkin DO, Sanli O, Yalin AS, Onem K, Kadioglu A. Obesity might not be a risk factor for female sexual dysfunction. BJU Int. 2010;106(9):1357-61.

2. Nguyen RH, Wilcox AJ, Skjaerven R, Baird DD. Men's body mass index and infertility. Hum Reprod. 2007;22(9):2488-93.

3. Melin I, Falconer C, Rossner S, Altman D. Sexual function in obese women: impact of lower urinary tract dysfunction. Int J Obes (Lond). 2008;32(8):1312-8.

4. Smith AM, Patrick K, Heywood W, Pitts MK, Richters J, Shelley JM, et al. Body mass index, sexual difficulties and sexual satisfaction among people in regular heterosexual relationships: a population-based study. Intern Med J. 2012;42(6):641-51.

5. Assimakopoulos K, Panayiotopoulos S, Iconomou G, Karaivazoglou K, Matzaroglou C, Vagenas K, et al. Assessing sexual function in obese women preparing for bariatric surgery. Obes Surg. 2006;16(8):1087-91.

6. van Hout GC, Hagendoren CA, Verschure SK, van Heck GL. Psychosocial predictors of success after vertical banded gastroplasty. Obes Surg. 2009;19(6):701-7.

7. Dixon JB, Dixon ME, O'Brien PE. Quality of life after lap-band placement: influence of time, weight loss, and comorbidities. Obes Res. 2001;9(11):713-21.

8. Tiggemann M. Body dissatisfaction and adolescent self-esteem: prospective findings. Body Image. 2005;2(2):129-35.

9. Assimakopoulos K, Karaivazoglou K, Panayiotopoulos S, Hyphantis T, Iconomou G, Kalfarentzos F. Bariatric surgery is associated with reduced depressive symptoms and better sexual function in obese female patients: a one-year follow-up study. Obes Surg. 2011;21(3):362-6.

10. Esposito K, Giugliano D. Obesity, the metabolic syndrome, and sexual dysfunction. Int J Impot Res. 2005;17(5):391-8. 
11. Kolotkin RL, Binks M, Crosby RD, Ostbye T, Gress RE, Adams TD. Obesity and sexual quality of life. Obesity (Silver Spring). 2006;14(3):472-9.

12. Miner PJ. Economic and personal impact of fecal and urinary in continence. Gastroenterology. 2004;126(1 Suppl1):S8-13.

13. Schwartz MB, Brownell KD. Obesity and body image. Body image. 2004;1(1):43-56.

14. Kinzl JF, Trefalt E, Fiala M, Hotter A, Biebl W, Aigner F. Partnership, sexuality, and sexual disorders in morbidly obese women: consequences of weight loss after gastric banding. Obes Surg. 2001;11(4):455-8.

15. White MA, O'Neil PM, Kolotkin RL, Byrne TK. Gender, race, and obesity-related quality of life at extreme levels of obesity. Obes Res. 2004;12(6):949-55.

16. Muennig P, Lubetkin E, Jia H, Franks P. Gender and the burden of disease attributable to obesity. Am J Public Health. 2006;96(9):1662-8.

17. Addis IB, Van Den Eeden SK, Wassel-Fyr CL, Vittinghoff E, Brown JS, Thom DH, et al. Sexual activity and function in middle-aged and older women. Obstet Gynecol. 2006;107(4):755-64.

18. Esposito K, Ciotola M, Giugliano F, Bisogni C, Schisano B, Autorino R, et al. Association of body weight with sexual function in women. Int J Impot Res. 2007;19(4):353-7.

19. Jaafarpour M, Khani A, Khajavikhan J, Suhrabi Z. Female sexual dysfunction: prevalence and risk factors. J Clin Diagn Res. 2013;7(12):2877-80.

20. Duval K, Marceau P, Lescelleur O, Hould FS, Marceau S, Biron S, et al. Health-related quality of life in morbid obesity. Obes Surg. 2006;16(5):574-9.

21. Esposito K, Giugliano F, Di Palo C, Giugliano G, Marfella R, D'Andrea F, et al. Effect of lifestyle changes on erectile dysfunction in obese men: a randomized controlled trial. JAMA. 2004;291(24):2978-84.

22. Reischer E, Koo KS. The body beautiful: Symbolism and agency in the social world. Annu Rev Anthropol. 2004:297-317.

23. Bajos N, Wellings K, Laborde C, Moreau C, C. S. F. Group . Sexuality and obesity, a gender perspective: results from French national random probability survey of sexual behaviours. BMJ. 2010;340:c2573.
24. Mohammadi Kh, Heydari M, Faghihzade S. [Validity ofthe Persian version of the female sexual function index (FSFI) as an indicatorof women's sexualfunction.] Payesh. 2008;7(3):269-78.

25. Rosen R, Brown C, Heiman J, Leiblum S, Meston C, Shabsigh R, et al. The Female Sexual Function Index (FSFI): a multidimensional self-report instrument for the assessment of female sexual function. J Sex Marital Ther. 2000;26(2):191-208.

26. Esposito K, Ciotola M, Marfella R, Di Tommaso D, Cobellis L, Giugliano D. The metabolic syndrome: a cause of sexual dysfunction in women. Int J Impot Res. 2005;17(3):224-6.

27. Mathus-Vliegen EM, de Wit LT. Health-related quality of life after gastric banding. BrJSurg. 2007;94(4):457-65.

28. Bond DS, Wing RR, Vithiananthan S, Sax HC, Roye GD, Ryder BA et al. Significant resolution of female sexual dysfunction after bariatric surgery. Surg Obes Relat Dis. 2011;7(1):1-7.

29. Bond DS, Vithiananthan S, Leahey TM, Thomas JG, Sax HC, Pohl $D$, et al. Prevalence and degree of sexual dysfunction in a sample of women seeking bariatric surgery. Surg Obes Relat Dis. 2009;5(6):698-704.

30. Adolfsson B, Elofsson S, Rossner S, Unden AL. Are sexual dissatisfaction and sexual abuse associated with obesity? A populationbased study. Obes Res. 2004;12(10):1702-9.

31. Ball K, Crawford D, Kenardy J. Longitudinal relationships among overweight, life satisfaction, and aspirations in young women. Obes Res. 2004;12(6):1019-30.

32. Kapoor DS, Davila GW, Rosenthal RJ, Ghoniem GM. Pelvic floor dysfunction in morbidly obese women: pilot study. Obes Res. 2004;12(7):1104-7.

33. Yaylali GF, Tekekoglu S, Akin F. Sexual dysfunction in obese and overweight women. Int J Impot Res. 2010;22(4):220-6.

34. Kirchengast S, Hartmann B, Gruber D, Huber J. Decreased sexual interest and its relationship to body build in postmenopausal women. Maturitas. 1996;23(1):63-71.

35. Brody S. Slimness is associated with greater intercourse and lesser masturbation frequency. J Sex Marital Ther. 2004;30(4):251-61.

36. Kim KK, Kang HC, Kim SS, Youn BB. Influence of weight reduction by sibutramine on female sexual function. Int J Obes (Lond). 2006;30(5):758-63. 